\title{
mundo estranho de Twin Peaks: um pequeno marco nos seriados de televisão ${ }^{1}$
}

\author{
Rogério Ferraraz (Universidade Anhembi Morumbi ) ${ }^{2}$
}

\section{Resumo}

O trabalho visa analisar Twin Peaks, programa criado por David Lynch e Mark Frost, em 1990, que se tornou um marco na televisão, estabelecendo novos rumos e modelos para as narrativas seriadas. A recorrência ao estranho e ao grotesco e as relações com obras de cineastas e artistas distintos, principalmente surrealistas e expressionistas, são alguns dos elementos estudados para demonstrar como é possível desenvolver com qualidade produtos midiáticos de entretenimento.

Palavras-chaves: Narrativa seriada; Twin Peaks; estranho; cult. entretenimento.

\section{Abstract}

The present work intends to analyze the Twin Peaks show, created by David Lynch and Mark Frost in 1990. It became a television example, establishing new paths and models to series narratives. The recurence of what is odd and grotesque as well as the connections with the work of different filmmakers and artists, mainly surrealist and expressionist ones, are some of the elements we observe. We intend to demonstrate how it is possible to produce quality mediatic entertainment.

Keywords: Series narratives; Twin Peaks; odd; cult entertainment 
Uma premissa intrigante, que serve como ponto de partida para um seriado marcado por diversas tramas que se entrelaçam. Vários personagens centrais, cada um com uma história pregressa secreta e repleta de passagens obscuras que, aos poucos, vai sendo revelada. Acontecimentos estranhos, bizarros, que se sucedem, envolvendo praticamente todos os personagens. Perguntas sem respostas; poucas certezas, muitas dúvidas.

Se, com esse início, tem-se a impressão de que falamos de Lost, seriado exibido, desde 2004, pela rede norte-americana ABC, ledo engano. Trata-se, aqui, de resgatar o programa que fez uma pequena revolução nas narrativas seriadas no início dos anos 90 , alçando a um novo patamar o entretenimento televisivo e abrindo caminho para outros seriados de sucesso, como o próprio Lost, por exemplo.

Em 1990, mesmo ano em que recebeu a Palma de Ouro no Festival de Cinema de Cannes, por Coração selvagem (Wild at Heart, EUA, 1989), o cineasta David Lynch criou, para a $\mathrm{ABC}$, o seriado Twin Peaks ${ }^{3}$, em parceria com Mark Frost, que já havia trabalhado na televisão nos anos 80 , colaborando no seriado Hill Street Blues, e com quem Lynch havia escrito o roteiro, nunca filmado, de One Saliva Bubble (LYNCH; FROST, 1987). O programa teve, inicialmente, sete episódios semanais. Contrariando as pessimistas expectativas dos empresários, Twin Peaks tornou-se logo um sucesso e uma mania nos Estados Unidos (e, assim como o recente Lost, também salvou a $A B C$ da falência). Uma pergunta se espalhou rapidamente entre os telespectadores norte-americanos desde a noite de 08 de abril, quando foi ao ar o episódio piloto: "Quem matou Laura Palmer?". Tal sucesso fez com que o programa tivesse continuação e a segunda temporada começou a ir ao ar a partir de setembro daquele mesmo ano - até ser encerrado em junho de 1991, no $30^{\circ}$ episódio (ou $29^{\circ} \mathrm{b}$, como os criadores chamaram-no), após perder público e entrar em declínio de audiência. Foi nesse último ano, no entanto, que o seriado foi exibido em vários países e tornou-se um sucesso mundial tardio.

A trama se passa na pequena cidade de Twin Peaks, próxima à fronteira com o Canadá, onde é encontrada morta, envolta por um saco plástico, a garota mais popular do lugar: a jovem Laura (Sheryl Lee, que também interpreta a prima de Laura, Maddy). Um agente especial do FBI, Dale Cooper 
(Kyle MacLachlan), é chamado para comandar as investigações, junto com o xerife local, Harry Truman (Michael Ontkean). A partir daí, tem início um verdadeiro desenrolar de fatos inusitados e bizarros e acontecimentos fantásticos, que acabam mostrando que todos ali têm algo a esconder absolutamente todos os personagens guardam segredos e têm estórias próprias desenvolvidas na trama. Assim, para solucionar o assassinato, o agente terá que descobrir o lado oculto e os segredos dos indivíduos de Twin Peaks - e também os seus próprios, iniciando um mergulho através das representações do seu inconsciente, marcado formalmente pelas suas gravações em cassete a uma suposta (e desconhecida para o telespectador) Diane. Dale Cooper contará com métodos incomuns, num caso que envolverá tanto personagens vivos quanto espíritos de um outro mundo.

Após Twin Peaks e Coração selvagem, que Ihe renderam fama e prestígio mundial - e também alguns detratores, principalmente em relação ao longa - Lynch entrou num período conturbado em sua carreira, participando, ora como diretor, ora como produtor, de trabalhos para a televisão que não vingaram, apesar de suas qualidades: Crônicas americanas (American Chronicles, EUA, 1991), Hotel Room (EUA, 1992) e On the Air (EUA, 1992).

Em 1992, após essas tentativas fracassadas de reencontrar o sucesso de público da primeira temporada de Twin Peaks na televisão, mas ainda colhendo os frutos do bem sucedido seriado em todo o mundo, Lynch realizou um longa-metragem para o cinema: Twin Peaks - Os últimos dias de Laura Palmer (Twin Peaks - Fire Walk with Me, EUA, 1992).

O filme, em que Lynch se aprofunda ainda mais na fusão entre sonho e realidade, começa com o aparecimento do corpo de uma mulher, Teresa Banks, boiando num rio, na cidade de Deer Meadow, um ano antes da morte de Laura Palmer. Um agente do FBI, Chester Desmond (Chris Isaac), inicia as investigações mas logo some misteriosamente. $\mathrm{O}$ agente Dale Cooper (Kyle MacLachlan) assume em seu lugar. A ação transporta-se, então, para a cidade de Twin Peaks, na última semana da vida de Laura (Sheryl Lee). Algumas questões deixadas em aberto na série são abordadas agora por Lynch, como, por exemplo, a vida dupla (ou múltipla) de Laura: anjo/demônio, boa/má, inocente/culpada, etc. 
Como o longa dialoga com o seriado e o completa, neste texto iremos recorrer a ele com freqüência, mas sempre com o objetivo de jogar luzes sobre o programa televisivo, na tentativa de esmiuçar alguns elementos que fizeram de Twin Peaks um marco na televisão mundial, especialmente na norteamericana - Arlindo Machado coloca a primeira temporada do seriado como um dos programas de destaque da história da televisão (MACHADO, 1998: 18).

Para tanto, elegemos alguns pontos que consideramos essenciais na análise do seriado. Para compreendermos a riqueza e a complexidade de Twin Peaks, devemos buscar subsídios em diversas áreas, como, por exemplo, a História da Arte e a do Cinema. Além disso, procuraremos mostrar também como o seriado liga-se a outras obras de Lynch, o que o insere num projeto criativo muito maior e interessante, que parece propor uma espécie de quebracabeça imagético e sonoro em que as peças vão sendo espalhadas aos poucos por diversas mídias diferentes. Todo esse amalgama estético, artístico e narrativo foi um dos diferenciais que fizeram do seriado objeto de culto e de reflexão e que acabaram por transformá-lo em modelo para programas posteriores. $^{4}$

\section{O alfabeto de BOB}

Tomadas de lanchonetes, postos de gasolina, semáforos, ruas - sempre com um caminhão carregado de madeira estacionado ou passando em frente à câmera - preenchem o seriado de imagens típicas dos quadros de Edward Hopper, um dos pintores admirados por Lynch. Representante da tradição realista do preciosismo, as telas de Hopper são dotadas de um colorido frio adquirido por uma técnica perfeita, lançando um olhar crítico sobre o cotidiano das cidades americanas. Em Twin Peaks, porém, esse cotidiano é mostrado com um preciosismo exagerado a tal ponto que passa a gerar angústia, tensão e incômodo.

Vários exemplos poderiam ser retirados do seriado para demonstrar como Lynch faz o normal parecer anormal, o convencional, anticonvencional, o familiar, estranho. É justamente o estranho, o efeito de estranhamento decorrente da transformação do comum em incomum, do ordinário em 
extraordinário, que grande parte dos trabalhos de Lynch causa, inclusive o seriado Twin Peaks.

Por isso, é inevitável que se retome um dos conceitos de Sigmund Freud, o de unheimlich, ou estranho, definido por ele num texto de 1919, intitulado justamente Das Unheimliche. Para exemplificar o que seria o estranho, ligado aos elementos conhecidos e familiares, Freud utilizou-se do conto O homem da areia, do escritor alemão E. T. A. Hoffmann.

O unheimlich relaciona-se com o que é assustador, com o que provoca horror e medo. Freud, no entanto, pontua que: "De início, abrem-se-nos dois rumos. Podemos descobrir que significado veio a ligar-se à palavra 'estranho' no decorrer da sua história; ou podemos reunir todas aquelas propriedades de pessoas, coisas, impressões sensórias, experiências e situações que despertam em nós o sentimento de estranheza, e inferir, então, a natureza desconhecida do estranho a partir de tudo o que esses exemplos têm em comum. Direi, de imediato, que ambos os rumos conduzem ao mesmo resultado: o estranho é aquela categoria do assustador que remete ao que é conhecido, de velho, e há muito familiar.” (FREUD, 1976: 277)

Lynch mostra que nos próprios ambientes "seguros" da família escondem-se elementos sinistros e perturbadores. Em Twin Peaks, o Mal encontra-se dentro de casa, pois é o próprio pai de Laura Palmer, Leland (Ray Wise), possuído pelo espírito de BOB (Frank Silva), que transa com ela todas as noites e acaba matando-a - além disso, todas as famílias de Twin Peaks, tanto no seriado de TV quanto no longa, guardam segredos que podem, caso revelados, destruir a tranqüilidade aparente daquela cidade.

O estranho lynchiano é revestido ainda pela forma como ele foca seus personagens e retrata o corpo humano, envolvendo sua obra no grotesco, que assume um tom surreal. Os surrealistas tinham obsessão em retratar o corpo em partes fragmentadas ou sendo cortado. Essa característica pode ser observada, por exemplo, em fotografias de Man Ray, como Lips of Lee Miller, Torso e Dora Maar. Na escultura, há o exemplo de Vênus de Milo com gavetas, de Salvador Dalí - a imagem da Vênus de Milo vai aparecer freqüentemente nos trabalhos de diversos surrealistas, como, por exemplo, em Venus restaurée, de Man Ray. Na literatura, o corte do corpo humano é um dos temas centrais de História do olho, de Georges Bataille (BATAILLE, 1981). Na pintura, 
podem ser citados Equilíbrio Intra-Atômico de Uma Pena de Cisne, de Dalí, Mão, de Man Ray, Eterna Evidência e O Modelo Vermelho, de René Magritte, bem como os quadros em que Vitor Brauner se auto-retratava, sempre tendo um olho perfurado. No cinema, a abertura de Um cão andaluz (Um Chien Andalou, França, 1928), de Luis Buñuel e Salvador Dalí, com a navalha cortando o olho de uma mulher, e a perna amputada de Catherine Deneuve, em Tristana, paixão mórbida (Tristana, França, 1970), também de Buñuel, são dois exemplos famosos.

Nos trabalhos de Lynch, esse tema também é fundamental, conforme comprova a tão comentada cena da orelha decepada encontrada em Veludo azul (Blue Velvet, EUA, 1986), por exemplo. A própria imagem da Vênus de Milo, com seus braços arrancados, também tem seu espaço garantido na obra de Lynch, como se pode ver em várias seqüências de Twin Peaks, passadas no Black Lodge - uma espécie de outro mundo habitado por personagens bizarros que, possivelmente, são espíritos.

Além do trabalho com o corpo fragmentado, que afronta a "normalidade" do mundo - principalmente a baseada nas convenções do belo e do sublime -, Lynch focaliza figuras que fogem do dito padrão normal, tais como os anões, os gigantes, os cegos, os deformados e os aleijados. Exemplos não faltam em Twin Peaks: o Anão (também chamado de O Homem no Outro Mundo), ${ }^{\mathbf{5}} \mathrm{O}$ Gigante, e um homem sem o braço esquerdo, Mike, são personagens que têm relações fundamentais com os estranhos acontecimentos da narrativa.

Paralelamente e de forma análoga ao corpo fragmentado, Lynch apresenta também, em suas obras, experimentos com a fragmentação da linguagem. No quadro So This Is Love, observa-se a utilização das letras maiúsculas separadas formando o título da obra, desenhadas como se fossem datilografadas em pequenos papéis recortados. Um motivo lingüístico recorrente em muitos quadros de Lynch, como Ants In My House ou Red Headed Party Doll, foi também utilizado em Twin Peaks e Os últimos dias de Laura Palmer, em que o espírito assassino BOB (cujo nome original era RoBerTson) insere as letras $\mathrm{R}, \mathrm{B}$, e $\mathrm{T}$ embaixo das unhas de suas vítimas, numa macabra e narcisística forma de marcar a autoria de seus crimes. 
Essa presença constante de letras nas obras de Lynch demonstra uma obsessão com o alfabeto, nascida e cultivada numa relação de fascínio e aversão. Um bom exemplo é o curta The Alphabet (EUA, 1968), em que uma garota (Peggy Lynch) tem pesadelo com as letras do alfabeto e acorda vomitando.

Michel Chion observou, em sua aguda análise do curta, que The Alphabet poderia assumir, para alguns olhares, um caráter antecipatório de outras obras de Lynch, principalmente de Twin Peaks: "Given Lynch's description of The Alphabet as a film about pedagogical force-feeding, one may be tempted to see Bob as a teacher who is rather over-zealous in bringing his young female students to assimilate the alphabet, to the point of having them literally incorporate it". (CHION, 1995: 162)

Essa recorrência de Lynch ao alfabeto é uma amostra do uso que ele faz de elementos derivados da infância, portanto, familiares, para criar situações de angústia, deixando aflorar na tela os medos e os temores escondidos no inconsciente humano. Medos traduzidos numa forma narrativa que privilegia os efeitos de estranheza, reforçados pela presença do grotesco, em imagem e som.

Outra forma como o estranho apresenta-se em Twin Peaks é pela aparição fantasmagórica do duplo, que se torna parte essencial da estória. São muitas as figuras duplicadas: Leland Palmer e BOB, Laura Palmer e sua prima Maddy Ferguson, Cooper e seu doppelgänger, etc.

O caso de $\mathrm{BOB}$ e Cooper é o mais intrigante, pois eles são, respectivamente, o vilão e o herói do programa. No entanto, são opostos que se completam. Nada mais pertinente que Twin Peaks terminar com o espírito de $\mathrm{BOB}$ se apossando do duplo de Cooper. No último episódio, dirigido por Lynch e escrito por Mark Frost, Harley Peyton e Robert Engels (este último seria, posteriormente, autor, junto com Lynch, do roteiro de Os últimos dias de Laura Palmer), Cooper entra no Black Lodge, o lugar habitado pelos espíritos, para tentar salvar sua namorada, Annie Blackburn (Heather Graham), levada para lá por Windom Earle (Kenneth Welsh), inimigo de Cooper. Numa bela e memorável seqüência que dura aproximadamente quatorze minutos (um tempo enorme para a televisão), Cooper entra e sai de diversos quartos, atravessando 
as cortinas vermelhas que os separam e encontrando diversos personagens da estória. Num desses momentos, o Anão - que parece ser o comandante daquele lugar - anuncia: "Doppelgänger!" Vê-se, então, surgir outro Cooper, o duplo, que passa a perseguir o primeiro. É o doppelgänger que, ao final, sai do Black Lodge com Annie e é resgatado pelo xerife Truman, que não percebe tratar-se de um duplo.

Esses efeitos ligados às questões de alteridade e de duplicidade estão relacionados também à presença de espelhos, indicando uma intenção de discutir os limites da identidade. Apesar de lembrar alguns quadros e passagens de filmes expressionistas, a forma com que Lynch usa os espelhos ou as imagens refletidas também se aproxima de algumas técnicas do Surrealismo. Vários artistas surrealistas utilizaram a imagem do objeto espelho para discutir as fronteiras entre o eu e o outro, o real e o representado, o material e o imaterial. Um dos quadros mais famosos de Magritte, $A$ reprodução interdita (retrato de Edward James), mostra a figura de um homem, de costas, olhando para o espelho. Sua imagem refletida também está de costas, contrariando a lógica racional do que seria um reflexo tradicional. Para tornar a imagem ainda mais intrigante, Magritte pintou um exemplar de $A s$ aventuras de Arthur Gordon Pym, de Edgar Allan Poe, refletido da maneira tradicional.

O agente Dale Cooper, de Twin Peaks, é bem semelhante a essa figura magrittiana, com terno preto e penteado impecável. ${ }^{6}$ Uma cena-chave no longa Os últimos dias de Laura Palmer retoma algumas questões presentes no quadro de Magritte. Em vez de um espelho, há um circuito interno de vídeo, no prédio do FBI na Filadélfia. Cooper olha para a câmera num corredor e entra na sala de controle para ver o que aquela câmera registra. Na terceira vez que faz isso, ele vê sua própria imagem congelada no monitor, enquanto o agente Phillip Jeffries (David Bowie) passa ao lado dela. A seqüência, assim como o espelho de Magritte, contraria as leis da física, atualizando e presentificando na diegese do filme um personagem que provavelmente está morto - é dito que ele havia sumido há anos e, na seqüência seguinte, desaparece como se fosse um fantasma.

Lynch questiona, aqui, a indexicalidade da imagem fotográfica, ou no caso, videográfica, negando que funcione como prova cabal de um fato 
acontecido. Lembramos que Umberto Eco já chamara a imagem fotográfica de "espelho congelante", sobre cuja superfície congela-se a imagem refletida quando o objeto desaparece. (ECO, 1989: 33) E Arlindo Machado classificara de "ilusão especular" o efeito causado pela imagem fotográfica, lembrando que a fotografia, "desde os primórdios de sua prática, tem sido conhecida como o 'espelho do mundo', só que um espelho dotado de memória." (MACHADO, 1984: 10-11)

Lynch, assim como Magritte, vira a lógica do avesso: em uma cena do seriado, o olho de Laura Palmer, congelado num frame de um vídeo, reflete o que está fora dele, o guidão da motocicleta de James Hurley (James Marshall), seu namorado secreto, que havia gravado as imagens durante um piquenique. O mesmo ocorre em O Espelho Falso, pintado por Magritte em 1935, em que, num olho gigante, está refletido o céu azul com nuvens brancas.

O espelho lynchiano parece refletir a alma e/ou o espírito de cada personagem, expondo sua realidade fragmentada, fraturada $e$, enfim, duplicada. Nesse espelho mágico, é o rosto de BOB, o espírito assassino, que aparece refletido nos espelhos contemplados por Leland Palmer e pelo duplo do agente Cooper. Em Twin Peaks, aliás, a primeira e a última pessoa que aparecem estão se olhando no espelho. Mas há uma diferença básica entre as duas imagens.

No episódio piloto, o seriado começa com a imagem de um robin (piscode-peito-ruivo) - o que já estabelece uma ponte com Veludo azul, como se um partisse do ponto onde o outro terminou, já que uma das últimas imagens daquele filme era a de um tordo, pássaro parecido com o robin, comendo um besouro. Depois aparecem imagens de uma madeireira e planos aproximados de uma serra cortando madeira - outra ligação evidente com Veludo azul, já que Lumberton, local onde a estória do filme acontecia, também era uma cidade madeireira. A música tem um tom melancólico. Corta-se, então, para uma estrada, com a placa ao lado direito: "Welcome to Twin Peaks / Population: 51.201". Novo corte, focaliza-se uma cachoeira, e depois o rio. As cenas são bucólicas, aparecem dois patos na água, com uma grande casa à beira do rio. A música, então, cessa e há novo corte. A câmera mostra a personagem interpretada por Joan Chen maquiando-se em frente a um espelho. O olhar dela parece perdido, talvez aprisionado naquela imagem 
refletida. Mais tarde, o telespectador saberá que se trata de Josie Packard, viúva de Andrew Packard e herdeira da grande madeireira, e descobrirá, durante o seriado, que ela tem vida dupla, que o marido dela não havia morrido de verdade etc., como se aquele quadro inicial já antecipasse que a obra se pautaria pelas desconfianças e dúvidas que a ilusão especular, princípio básico da imagem fotográfica (ou vídeo/cinematográfica), acarreta.

Já na seqüência derradeira de Twin Peaks, o doppelgänger - o duplo de Cooper - acorda num quarto, sendo observado pelo xerife Truman e pelo doutor Hayward (Warren Frost) - que não sabem tratar-se de um duplo -, repete duas vezes a frase "Eu preciso escovar meus dentes", vai ao banheiro e lá bate com sua cabeça no espelho. Quando a câmera o focaliza de perfil, em primeiro plano, seu rosto está sangrando, e a face de $\mathrm{BOB}$, o espírito assassino, está refletida no espelho quebrado.

\section{O assassino está entre nós}

Outra constante nos trabalhos de Lynch é a presença de círculos, espirais e do movimento circular. Os espirais de hipnotismo vistos no circo de horrores em O homem elefante (The Elephant Man, EUA, 1980); as imagens poéticas de Duna; e em Twin Peaks, o anel dourado - que serve como indício da morte para quem o usa -, o Círculo de 12 Sicômoros - que serve de passagem entre os mundos dos vivos e dos espíritos - e a xícara de café com a imagem refletida do rosto de Laura Palmer sobre a qual sobem os créditos finais no último episódio do seriado são apenas algumas amostras desse recurso.

O movimento e os elementos circulares são freqüentes na história do cinema, mas atingiram seu ápice no Expressionismo Alemão. Retomando as colocações de Siegfried Kracauer, os circos e parques são cenários privilegiados nos filmes expressionistas justamente porque reproduzem a idéia de círculo. Conforme o autor: "o círculo, neste caso, se torna um símbolo do caos. Enquanto a liberdade parece um rio, o caos parece um redemoinho. Esquecida de si mesma, uma pessoa pode mergulhar no caos; não pode se mover nele". (KRACAUER, 1988: 90) 
Apesar de não explorar cenários como parques de diversões - a não ser em $O$ homem elefante -, Lynch também estabelece, em seus filmes, uma relação entre o círculo e o caos: o caos, aqui, significa um não-controle dos personagens daquilo que acontece em suas vidas, como se estivessem fadados a um destino pré-estabelecido.

Exemplos não faltam para demonstrar como é possível observar certas características expressionistas nas obras de Lynch. Um filme daquele período, porém, tem particular relação com os trabalhos do diretor: $M$, o vampiro de Dusseldorf (M, Alemanha, 1930), de Fritz Lang.

O movimento levemente circular da câmera, em Veludo azul, por exemplo, entrando e saindo da orelha do protagonista Jeffrey (Kyle MacLachlan), remete ao universo psíquico-subjetivo do personagem. Apesar de se configurar a partir de um procedimento distinto, tal relação, entre narrador (câmera) e personagem (universo psíquico), faz lembrar da estrutura desenvolvida por Lang em $M$ - sendo que, neste, o elemento de destaque é o som, com a idéia de circularidade do leitmotif, em que a música assobiada pelo assassino liga-se ao seu processo crescente de esquizofrenia.

A crítica de cinema Pauline Kael já relacionara outro filme de Lynch com - clássico de Lang. Em sua crítica sobre Eraserhead (EUA, 1977), Kael escreveu sobre as semelhanças entre as ruas em que o assassino, interpretado por Peter Lorre, caminhava em $M$ e os locais percorridos pelo protagonista Henry (Jack Nance), no filme de Lynch (KAEL, 1994: 165).

Além de Eraserhead e Veludo azul, outras obras de Lynch parecem dialogar com M. O caso de Twin Peaks é o mais evidente. No episódio piloto, dirigido por Lynch e escrito por ele e Mark Frost, as formas como a mãe de Laura Palmer, Sarah (Grace Zabriskie), e os colegas da garota na escola tomam conhecimento de sua morte têm uma estrutura muito semelhante à desenvolvida por Lang, em $M$, para mostrar que a garotinha Elsie havia sido assassinada.

Elsie não voltou para casa no horário de costume. A mãe dela, preocupada, sai do apartamento e se debruça sobre o corrimão da escada vazia do prédio para chamar a filha. Volta, fecha a porta e olha para o relógio. Vai até a janela e olha para a rua. Grita o nome da filha novamente. A ausência da garota é evidenciada pela imagem, a mesa arrumada diante da cadeira 
vazia, e pelo som, o barulho do relógio que marca as horas. O assassinato, então, é sugerido, numa construção elíptica, pela presença dos objetos que Elsie segurava - a bola, que sai rolando detrás de uma moita, e o balão, que, solto no ar, se enrosca no fio elétrico - e pela ausência da menina. Imagens sobre as quais se prolonga o desesperado apelo da mãe - em off, o espectador continua a ouvir seus gritos, chamando a filha.

Em Twin Peaks, o telespectador já sabe que Laura está morta, mas sua mãe e seus amigos ainda não. Em casa, Sarah chama por Laura, pois esta já estaria atrasada para a escola. Como não obtém resposta, vai até a escada e a chama novamente. Sobe e procura pela filha nos quartos da casa. Já desesperada, telefona para o marido, Leland, no Great Northern Hotel, onde ele trabalha como advogado. Neste momento, o xerife Truman chega ao hotel. Quando Leland o vê, consegue pronunciar apenas "Xerife Truman..." e deixa o telefone cair. Sarah, agora histérica, descobre, do outro lado da linha, que sua filha morreu.

Na escola, a construção das cenas é similar: a imagem da cadeira, onde Laura costumava sentar, vazia; o policial que chama a professora até a porta, sussurra algo em seu ouvido e ela, então, olha para a cadeira, com um ar de tristeza e perplexidade; uma aluna que passa correndo e gritando do lado de fora da sala. Com estes elementos é que Donna Hayward (Lara Flynn-Boyle), melhor amiga de Laura, e James, o namorado secreto da garota, percebem que ela está morta.

Além desses procedimentos, outros aspectos podem ser discutidos. Em $M$, o assassino é dominado por uma incontrolável compulsão homicida, marcada pelo leitmotif da música/assobio. Suas palavras, durante o seu "julgamento" - feito pelos próprios bandidos da cidade -, tornam clara sua condição: "Mas eu... poderia ter sido outra coisa? Sabem da maldição que há dentro de mim? Já ouviram esta voz, conhecem minha tortura? (...) Só quando mato é que não penso em mais nada. Quem sabe o que vai dentro de mim e como tudo acontece? Não quero, mas eu preciso matar. Sou obrigado a matar."

Já em Twin Peaks, BOB (e, por tabela, Leland, que lhe empresta o corpo no mundo dos vivos) também está condenado a matar. Durante um sonho do agente Cooper, no terceiro capítulo, dirigido por Lynch e escrito por ele e por 
Frost, BOB anuncia: "Eu prometo que matarei de novo". A diferença crucial entre ambos é que, ao contrário de $M$, no trabalho de Lynch, além de haver a incorporação de um espírito - fato que distancia os assassinos das duas obras -, em nenhum momento, BOB demonstra sofrimento com sua condição, como faz o personagem de Lorre em $M$ - aliás, BOB nem ao menos considera sua condição uma maldição ou desgraça, ao contrário do sofrimento (aparente) de Leland, o que o aproxima, ainda mais do que a BOB, do assassino de $M$.

Além disso, assim como em $M$, a música funciona, em Twin Peaks, tanto como prenúncio quanto como testemunho da ação do assassino. Isso fica claro por uma das pistas seguidas por Cooper, "há sempre música no ar" - frase dita pelo Anão durante um sonho do agente - e pelo barulho feito, com as mãos e a boca, por esse mesmo Anão, imitando o som de um pássaro - provavelmente o piar de uma coruja, já que outra pista seguida por Cooper é "As corujas não são o que parecem", dita para ele, num outro sonho, pelo Gigante (Carel Struycken), no nono episódio, dirigido por Lynch e escrito por ele e por Frost. Em uma seqüência, no episódio seguinte, também sob direção de Lynch e escrito por Harley Peyton, há uma sobreposição do rosto de BOB com a imagem de uma coruja, evidenciando tal relação.

A coruja que fica à espreita, em Twin Peaks, parece se confundir com a própria floresta que habita, como se fosse um dos pássaros-folha da galeria de "criaturas-planta" pintadas por Magritte, que parecem brotar da rocha, como em Os Companheiros do Medo, de 1942. A escolha daquela determinada ave no seriado não é aleatória: as corujas são seres noturnos - os crimes de BOB e os principais fatos decorrem à noite - e têm o sentido auditivo muito apurado - 0 som é um dos elementos mais significativos nas obras de Lynch. $^{7}$

Outro dado fundamental e similar nas duas obras é que os assassinos vivem nas próprias comunidades em que os crimes acontecem. Tal fato aumenta a tensão e o mistério que envolvem a situação. Existem falas semelhantes nas duas obras. Em $M$, após o sumiço da garota Elsie - que já não era a primeira vítima -, os cidadãos se reúnem para decidir o que deve ser feito. Um deles comenta: "Quem é o assassino? Onde se esconde? Ninguém o conhece e, no entanto, está entre nós. Pode estar sentado junto de nós." Em Twin Peaks, ainda no episódio piloto, Dale Cooper e o xerife Truman reúnem as pessoas mais importantes da cidade num salão. Cooper, então, explica que 
tem fortes indícios de que Laura teria sido a segunda vítima do assassino - ele já teria matado, um ano atrás, Teresa Banks, na cidade de Deer Meadow (como vimos, crime que acabaria sendo o ponto de partida do longa Os últimos dias de Laura Palmer, filmado dois anos depois do seriado). O agente do FBI alerta a todos: "Há chances de que quem cometeu esses crimes seja alguém daqui. Alguém que vocês conhecem."

Concluindo, foi possível perceber, a partir das análises feitas, como Lynch e seus constantes colaboradores trabalharam, em um programa de televisão como Twin Peaks, com a junção de elementos narrativos e estéticos distintos, mas recorrentes, criando um universo próprio, "Iynchiano", facilmente reconhecível, assim como já ocorrera em outras obras do diretor, feitas para o cinema.

Essa construção de um universo próprio, particular é uma das características da chamada obra cult, que pode ser aplicada aos trabalhos do diretor. No texto de introdução para o livro que organizou sobre Twin Peaks, David Lavery lembra das colocações de Umberto Eco sobre o assunto. Uma das regras apontadas por Eco como um pré-requisito para que uma obra se torne cult é a capacidade de: "provide a completely furnished world so that its fans can quote characters and episodes as if they were aspects of the fan's private sectarian world, a world about which one can make up quizzes and play trivia games so that the adepts of the secret recognize through each other a shared experience". (Apud LAVERY, 1995: 7)

Twin Peaks é o maior exemplo desse "mundo próprio" criado por Lynch. ${ }^{8}$ Essa estratégia, aliada ao fato de esse "mundo" ter sido exibido pela televisão, tornou o seriado objeto de culto como nenhuma outra obra do diretor: até hoje é editada uma revista sobre a série, chamada Wrapped in Plastic - frase dita por Pete Martell (Jack Nance), no início do episódio piloto, quando ele liga para a delegacia para afirmar que encontrou o corpo de uma garota morta envolta em um saco plástico, que vem a ser Laura Palmer; são feitas convenções anuais de fãs de Twin Peaks na cidade em que a obra foi filmada, em que atores, roteiristas e diretores da série são convidados para dar palestras; etc.

Todos esses pontos servem para demonstrar como a televisão pode desenvolver produtos de qualidade, como Twin Peaks, que, a despeito de 
comentários equivocados, têm sim como uma de suas principais finalidades entreter e conquistar a audiência. 


\section{Referências bibliográficas}

BATAILLE, Georges. História do olho. São Paulo: Escrita, 1981.

CHION, Michel. David Lynch. Londres: British Film Institute, 1995.

ECO, Umberto. Sobre os espelhos e outros ensaios. Rio de Janeiro: Nova Fronteira, 1989.

FERRARAZ, Rogério. O cinema limítrofe de David Lynch. Tese (Doutorado em Comunicação e Semiótica). São Paulo: PUC, 2003.

FREUD, Sigmund. "O estranho". In: Obras psicológicas completas de Sigmund Freud (Vol. XVII). Rio de Janeiro: Imago, 1976. p. 271-318.

FROST, Scott. Dale Cooper: minha vida, minhas gravações / como foram ouvidas por Scott Frost. São Paulo: Globo, 1991.

HOFFMANN, E. T. A . Contos fantásticos. Rio de Janeiro: Imago, 1993.

KAEL, Pauline. 1001 noites no cinema. São Paulo: Companhia das Letras, 1994.

KRACAUER, Sigfried. De Caligari a Hitler: uma história psicológica do cinema alemão. Rio de Janeiro: Zahar, 1988.

LAVERY, David (ed.). Full of Secrets: Critical Approaches to Twin Peaks. Detroit, USA: Wayne State University, 1995.

LYNCH, David; ENGELS, Bob. Twin Peaks: Fire Walk With Me, Teresa Banks and the Last Seven Days of Laura Palmer. Roteiro (Shooting Draft), agosto de 1991.

LYNCH, David; FROST, Mark. Northwest Passage. Roteiro (Revised First Draft), dezembro de 1988.

One Saliva Bubble. Roteiro (First Draft), maio de 1987.

LYNCH, David; FROST, Mark; WURMAN, Richard Saul. Welcome to Twin Peaks: Access Guide to the Town. New York: Pocket Books, 1991.

LYNCH, Jennifer. O diário secreto de Laura Palmer: visto por Jennifer Lynch. 5.ed. São Paulo: Globo, 1996.

MACHADO, Arlindo. "Televisão: a questão do repertório". In: Revista IMAGENS. No. 8. Campinas, SP: Unicamp, maio/agosto de 1998. p. 08-19. 
A ilusão especular. São Paulo: Brasiliense ; Rio de Janeiro: Instituto Nacional da Fotografia, 1984.

\author{
PALMER, Potter. Auteur TV: Twin Peaks, Quality TV and the Cultivated \\ Audience. Tese (Department of Film and Television). Los Angeles: UCLA, \\ 1997.
}

\begin{abstract}
${ }^{1}$ Este artigo teve uma primeira versão apresentada originalmente junto ao Grupo de Trabalho "Mídia e Entretenimento", do XVI Encontro da Compós, na UTP, em Curitiba, PR, em junho de 2007, publicada nos anais do evento e disponibilizada no website www.compos.org.br com o título "Bizarria e mistério na TV: Twin Peaks e o entretenimento de qualidade".

${ }^{2}$ Doutor em Comunicação e Semiótica pela PUC-SP, autor da tese "O cinema limítrofe de David Lynch" e professor do Mestrado em Comunicação da Universidade Anhembi Morumbi/SP. E-mail: rferraraz@anhembi.br.

${ }^{3}$ Vale registrar que o título do seriado seria Northwest Passage (LYNCH; FROST, 1988), e referia-se à fronteira - portanto, à passagem - entre os territórios do noroeste norte-americano e o Canadá. Além disso, funcionava como uma metáfora para a passagem entre o mundo dos vivos e o dos espíritos, um dos temas centrais da história. Em entrevista, Lynch explicou que a razão da mudança do título foi porque já havia um filme antigo com o mesmo nome (FERRARAZ, 2003, p. 201). Trata-se de $A$ passagem do noroeste (Northwest Passage, EUA, 1940), dirigido por King Vidor. Lynch apreciava o título original, mas também gostou de Twin Peaks, cidade próxima a duas montanhas idênticas, Whitetail e Blue Pine, os "Picos Gêmeos" (LYNCH; FROST, 1988, p. 1).

${ }^{4}$ Vale dizer que, apesar de caracterizar, por vezes, o diretor Lynch como um autor, utilizando o adjetivo "lynchiano" e centrando as considerações sobre o seriado apenas na figura dele, acredito ser esse autor Lynch uma soma de esforços criativos, envolvendo todos os outros profissionais que, com ele, trabalham com freqüência. Em relação ao seriado, então, essa observação torna-se ainda mais necessária, tendo em vista a pluralidade de diretores e roteiristas que trabalharam nos 30 episódios - não se pode esquecer, principalmente, da figura de Mark Frost, criador do programa junto com Lynch. A questão da autoria e da discussão sobre programas de qualidade na televisão em torno do fenômeno de Twin Peaks valeu, inclusive, uma tese, defendida por Potter Palmer na UCLA Los Angeles, em 1997, intitulada "Auteur TV: Twin Peaks, Quality TV and the Cultivated Audience" (PALMER, 1997).

${ }^{5} \mathrm{O}$ Anão é interpretado por Michael J. Anderson, ator anão que reapareceria em Industrial Symphony no. 1, Os últimos dias de Laura Palmer e Cidade dos sonhos. Entre 2003 e 2005, ele estrelou outro seriado, Carnivàle, na rede HBO, programa influenciado, conforme comentários de diversos especialistas, por Twin Peaks e pelos trabalhos de Lynch em geral.

${ }^{6}$ A caracterização de Cooper é muito parecida com o jeito de ser do próprio Lynch - e também com o personagem do diretor no seriado, o superior de Cooper no FBI, Gordon Cole, sendo que ambos repetem ainda os mesmos gestos, como, por exemplo, fazer o sinal de positivo com os dedos. Além disso, o ator Kyle MacLachlan é muito parecido físicamente com Lynch, funcionando como uma espécie de alter-ego do cineasta. Vale lembrar que MacLachlan já havia protagonizado Duna (Dune, EUA, 1984) e Veludo azul antes de Twin Peaks.
\end{abstract}

${ }^{7}$ A presença de corujas também lembra o Homem da Areia do conto homônimo de E. T. Hoffmann, estudado por Freud em $O$ estranho. Tal figura, conforme descrito por Natanael, protagonista da estória, era um ser monstruoso, que arrancava os olhos das crianças para alimentar seus filhotes, que tinham bicos retorcidos de coruja. (HOFFMANN, 1993)

${ }^{8}$ Lynch e Mark Frost também alimentaram essa paixão dos fanáticos seguidores lançando: um guia (fictício) chamado Welcome to Twin Peaks (LYNCH; FROST; WURMAN, 1991); o diário secreto de Laura Palmer, escrito por Jennifer Lynch, filha de David (LYNCH, 1996); e as transcrições das fitas cassete do agente Dale Cooper, escritas por Scott Frost, um dos roteiristas de Twin Peaks (FROST, 1991). 